\title{
INVESTIGATION OF LONGITUDINAL CRACKING IN WIDENED CONCRETE PAVEMENTS
}

2020/15(1)

Received 27 November 2018; accepted 20 August 2019

\begin{abstract}
Widened slabs, widely employed in many US states in concrete pavements, have suffered from unexpected longitudinal cracks. These cracks suddenly appeared within $0.60 \mathrm{~m}$ to $1.20 \mathrm{~m}$ from widened slab edges and could be detrimental to the long-term pavement performance. The primary objective of this study was to identify possible causes for such longitudinal cracking observed on widened concrete pavements. Both field investigation and Finite Element Analysis were performed. Degrees of curling and warping were measured using a Terrestrial Laser Scanner. Concrete cores were also extracted to achieve a better understanding of how the cracking had developed. Field survey and numerical simulation results indicate that such longitudinal cracks could be primarily caused by a combination of excessive traffic loads, a high degree of curling and warping, inadequate support from underlying layers,
\end{abstract}

\footnotetext{
* Corresponding author. E-mail: alex19@iastate.edu

Shuo YANG (ORCID ID 0000-0002-2653-5199)

Yang ZHANG (ORCID ID 0000-0002-1150-5595)

Orhan KAYA (ORCID ID 0000-0001-6072-3882)

Halil CEYLAN (ORCID ID 0000-0003-1133-0366)

Sunghwan KIM (ORCID ID 0000-0002-1239-2350)

Copyright (C) 2020 The Author(s). Published by RTU Press

This is an Open Access article distributed under the terms of the Creative Commons Attribution License (http://creativecommons.org/licenses/by/4.0/), which permits unrestricted use, distribution, and reproduction in any medium, provided the original author and source are credited.
} 
pavement ageing, and skewed joints. It was also found that $4.30 \mathrm{~m}$ widened slabs coupled with tied Portland Cement Concrete shoulders outperformed others in terms of producing less cracking, even when they had experienced higher levels of truck traffic. The sites constructed in late afternoons also showed significantly less longitudinal cracks.

Keywords: curling and warping, field investigation, finite element analysis, longitudinal cracking, shoulder type, widened pavement.

\section{Introduction}

Since the 1990s, many states in the US have begun using widened slabs widths of $4.30 \mathrm{~m}$ (14 ft.), for lane construction as a means of transverse crack mitigation. For most widened pavement construction, traffic lanes were constructed using widened slabs, while passing lanes usually continued to be formed by regular slabs with $3.70 \mathrm{~m}$ (12 ft.)

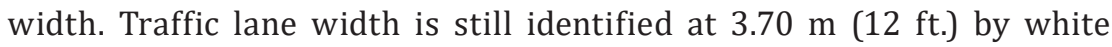

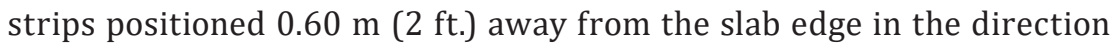
of traffic. The theory behind this practice was based on classic closedform equations from Westergaard (1926), who theorised that edge load was more critical than interior or corner loads (Westergaard, 1926). Consequently, the additional $0.60 \mathrm{~m}$ ( $2 \mathrm{ft}$.) widened slabs are beneficial to stresses and deflection reduction at critical slab edge location by moving the traffic path inward, thereby reducing shoulder maintenance costs and increasing the safety of maintenance crews as well (Applied Research Associates... , 2004; Lederle, 2014; Owusu-Ababio \& Schmitt, 2013; Sawan, Darter, \& Dempsey, 1982).

Even though widened Jointed Plain Concrete Pavement (JPCP) offer several advantages over conventional JPCP, it is thought that widened JPCP is particularly susceptible to longitudinal cracks (Applied Research Associates... , 2004; Lederle, 2014; Yu, Smith, \& Darter, 1995). It is well-known that Portland Cement Concrete (PCC) slabs tend to crack longitudinally when tensile stresses in the transverse direction exceed slab tensile strength. Various studies have verified that longitudinal cracks are resulted from several interrelated factors, including variations in temperature and moisture gradients, slab geometry, jointing practices (sawing timing, saw-cut depth, alignment of dowels), vibration, and support from underlying layers (Ardani, Hussain, \& LaForce, 2003; Chen \& Won, 2007; Owusu-Ababio \& Schmit, 2013; Voigt, 2002; Xiao \& Wu, 2018). However, there is a widespread belief that longitudinal cracking is primarily caused by poor construction practices and other non-load-related causes. Accordingly, the longitudinal cracking occurrence cannot be predicted using the Mechanistic-Empirical Pavement Design Guide (MEPDG) (Lederle, 2014; Xiao \& Wu, 2018). 
Recent studies have revealed that longitudinal cracks could be more dominant than transverse cracks as the principal failure modes in widened JPCPs sometimes (Kim, 2010; Owusu-Ababio \& Schmit, 2013; Raghavendra, Collier, \& Rupnow, 2017; Xiao \& Wu, 2018). Yu, Smith, \& Darter (1995) carried out a study to evaluate the performance of widened JPCPs with tied shoulders through both field and analytical investigations. They noted that tensile stresses imposed by curling dramatically increase slab edge stresses. Owusu-Ababio \& Schmit (2013) conducted a study investigating longitudinal cracks on widened slabs based on an online survey and a database of in-service doweled JPCPs from the Wisconsin Dept of Transportation (Wisconsin DOT).

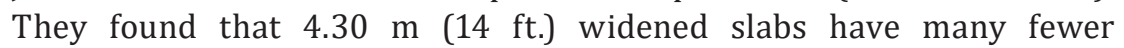
longitudinal cracks compared to those of $4.60 \mathrm{~m}$ (15 ft.) width. Use of a width-to-thickness $(\mathrm{w} / \mathrm{t}$ ) ratio in a range of 1.2 to 1.5 was suggested

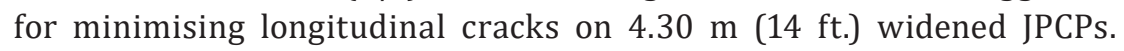
Another study carried on by Xu \& Cebon (2017) delved into the trends of longitudinal cracking in JPCPs by consulting Long-Term Pavement Performance (LTPP) databases from the states of Arizona and Arkansas. They concluded that the severity of longitudinal cracking is more sensitive to slab thickness and base type than slab width and PCC strength. Xiao \& Wu (2018) conducted a study to investigated longitudinal cracks on widened slabs in the state of Louisiana, with results indicating that use of $4.60 \mathrm{~m}$ (15 ft.) widened pavements coupled with tied PCC shoulders increased the likelihood of longitudinal cracking. The other contributing factors included inadequate longitudinal joint forming and base support.

The state of Iowa has adopted widened slabs in JPCP design and construction since 1992, and some of these slabs have exhibited sudden and significant longitudinal cracks (Ceylan, Kim, Yang, Kaya, Gopalakrishnan, Taylor, \& Yang, 2018). These pavements, typically constructed with skewed joints near the end of the 20th century and approaching 20 years of service life, were composed of $25.40 \mathrm{~cm}$ to $30.50 \mathrm{~cm}$ (10 in. to $12 \mathrm{in}$.) thick PCC layers laid on a $20.30 \mathrm{~cm}$ to $23.00 \mathrm{~cm}$ ( 8 in. to $9 \mathrm{in}$.) thick granular subbase layer. Field observations documented that, after 10 to 15 years of service life, these previouslyunreported cracks appeared at unexpected locations rather than at saw cut locations, and usually began from transverse joints as $10 \mathrm{~cm}$

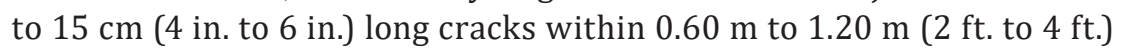
from the slab edge, and eventually became more developed in degree and severity. Since such unexpected cracks are injurious to the longterm performance of JPCP, it is of paramount importance to initiate an investigative study to determine potential contributing factors causing them. 
The overall objective of this study, therefore, is to identify possible causes of longitudinal cracking in widened JPCPs, so that recommendations for widened JPCP design features and construction practices will be provided to prevent such cracking. Field surveys were first performed at selected sites to identify cracking extent and severity. After such comprehensive data collection on in-service widened JPCPs, pavement performance and construction history of these sites were also carefully reviewed and evaluated. Concrete cores were also examined. Additionally, numerical analyses were also performed to investigate the impacts of temperature gradients and type of joints on longitudinal cracking.

\section{Field investigation}

With the intent of investigating the number and severity of longitudinal cracks in in-service widened JPCPs, field surveys were carried out between 2015 and 2018 at 12 selected sites. Although these

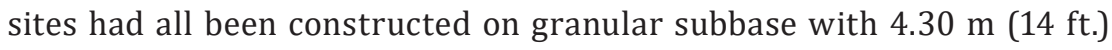

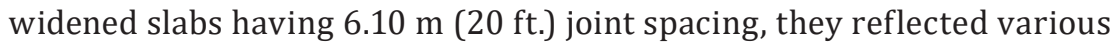
concrete mixtures, w/t ratio, traffic levels, construction years, and shoulder types (PCC, Hot Mix Asphalt (HMA), and granular shoulder). Such widened pavements, in service over 13 to 23 years, were already suffering from different levels of longitudinal cracking. Their slab thicknesses varied from $24.13 \mathrm{~cm}$ (9.5 in.) to $30.48 \mathrm{~cm}$ (12.0 in.). Values for average annual daily truck traffic $\left(\mathrm{AADT}_{\mathrm{T}}, \mathrm{vpd}\right)$, International Roughness Index (IRI, m/km), and Pavement Condition Index (PCI) were obtained from the 2015 Pavement Management Information Systems (PMIS) (Iowa Dept of Transportation, 2015). Table 1 summarises the basic information and geometry design features of the sites.

\subsection{Field observation}

At least one two-mile pavement section at each site was surveyed to record relevant information, including slab geometry, shoulder type, joint condition, amount and location of cracks, and severity level of cracks, following Distress Identification Manual for LTPP for Pavement Performance Assessment (Miller \& Bellinger, 2014). Drainage systems were also investigated by checking for the blockage of subsurface drainage system outlets. Other documentation, such as pavement construction reports, design plans, and historical pavement performance data, were also carefully reviewed and summarised. Figure 1 provides typical pictures of longitudinal cracking observed at site 10 , site 11 , and site 12 , respectively. 


\begin{tabular}{|c|c|c|c|c|c|c|c|c|c|c|}
\hline $\begin{array}{l}\text { Site } \\
\text { No. }\end{array}$ & 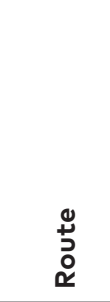 & 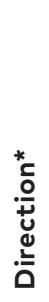 & 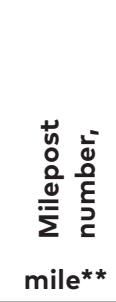 & 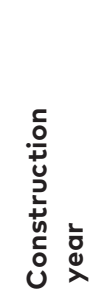 & 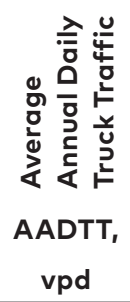 & 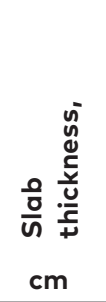 & 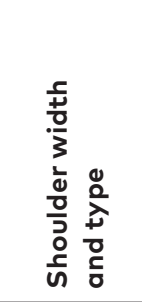 & $\begin{array}{l}\frac{0}{+0} \\
0 \\
\stackrel{2}{2} \\
3\end{array}$ & 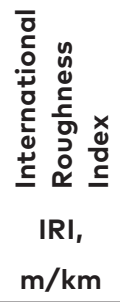 & 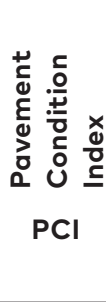 \\
\hline 1 & US 65 & 1 & 71.58 & 1997 & 1517 & 30.50 & $\begin{array}{c}2.40 \mathrm{~m} \\
\mathrm{PCC}\end{array}$ & 1.18 & 1.53 & 88 \\
\hline 2 & US 65 & 1 & 72.99 & 1997 & 1735 & 28.00 & $\begin{array}{c}2.40 \mathrm{~m} \\
\mathrm{PCC}\end{array}$ & 1.29 & 1.70 & 86 \\
\hline 3 & US 30 & 1 & 194.6 & 2005 & 1079 & 25.40 & $\begin{array}{l}1.20 \mathrm{~m} \\
\text { HMA }\end{array}$ & 1.41 & 1.39 & 81 \\
\hline 4 & US 61 & 1 & 30.32 & 1995 & 1153 & 25.40 & $\begin{array}{l}1.20 \mathrm{~m} \\
\mathrm{HMA}\end{array}$ & 1.41 & 1.44 & 80 \\
\hline 5 & US 65 & 2 & 78.70 & 1997 & 1178 & 30.50 & $\begin{array}{c}2.70 \mathrm{~m} \\
\mathrm{HMA}\end{array}$ & 1.18 & 1.66 & 84 \\
\hline 6 & IA 163 & 1 & 21.44 & 1996 & 1368 & 25.40 & $\begin{array}{l}1.20 \mathrm{~m} \\
\mathrm{HMA}\end{array}$ & 1.40 & 1.26 & 87 \\
\hline 7 & US 218 & 1 & 44.05 & 2001 & 1699 & 26.70 & $\begin{array}{l}1.20 \mathrm{~m} \\
\mathrm{HMA}\end{array}$ & 1.31 & 1.72 & 82 \\
\hline 8 & IA 92 & 1 & 235.09 & 2001 & 402 & 24.10 & $\begin{array}{c}4.40 \mathrm{~m} \\
\text { Granular }\end{array}$ & 1.47 & 2.22 & 74 \\
\hline 9 & US 30 & 2 & 159.85 & 1995 & 784 & 25.40 & $\begin{array}{c}2.90 \mathrm{~m} \\
\text { Granular }\end{array}$ & 1.40 & 1.64 & 86 \\
\hline 10 & US 30 & 2 & 261.2 & 1999 & 1191 & 25.40 & $\begin{array}{l}3.00 \mathrm{~m} \\
\text { Granular }\end{array}$ & 1.41 & 2.33 & 66 \\
\hline 11 & IA 163 & 1 & 44.99 & 1998 & 1585 & 25.40 & $\begin{array}{l}4.00 \mathrm{~m} \\
\text { Granular }\end{array}$ & 1.39 & 1.47 & 85 \\
\hline 12 & US 151 & 2 & 33.15 & 1999 & 2927 & 26.70 & $\begin{array}{c}2.70 \mathrm{~m} \\
\text { Granular }\end{array}$ & 1.33 & 2.30 & 57 \\
\hline
\end{tabular}

Note:

* 1 means eastbound or northbound and 2 means westbound or southbound;

** 1 mile $=1.609344 \mathrm{~km}$. 


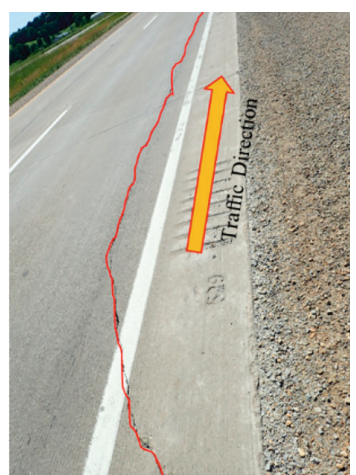

a) site 10 at US 30

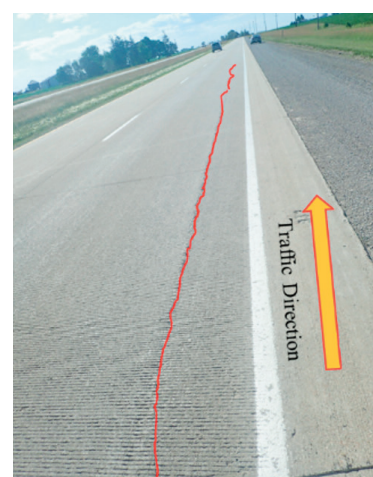

b) site 11 at IA 163

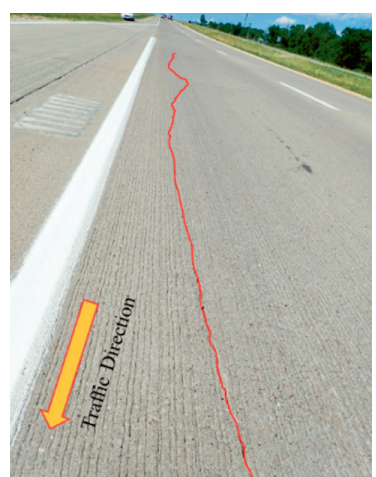

c) site 12 at US 151

Figure 1. Longitudinal cracking observed in the field

The survey results indicated that the majority of observed longitudinal cracks typically were initiated from transverse joints

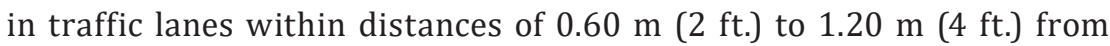
the slab edges. These cracks were near right wheel paths and parallel to pavement centrelines, and over time, they usually extended across two to three slabs. Longitudinal cracks beginning at the middle of the vertical edges in concrete patching areas were also observed; there is a possibility that such near-patching cracks had already existed before patching was performed. It was also noticed that while no cracks were found at site 1 during the survey conducted during the summer of 2017, a few longitudinal hairline cracks were found to have been initiated at

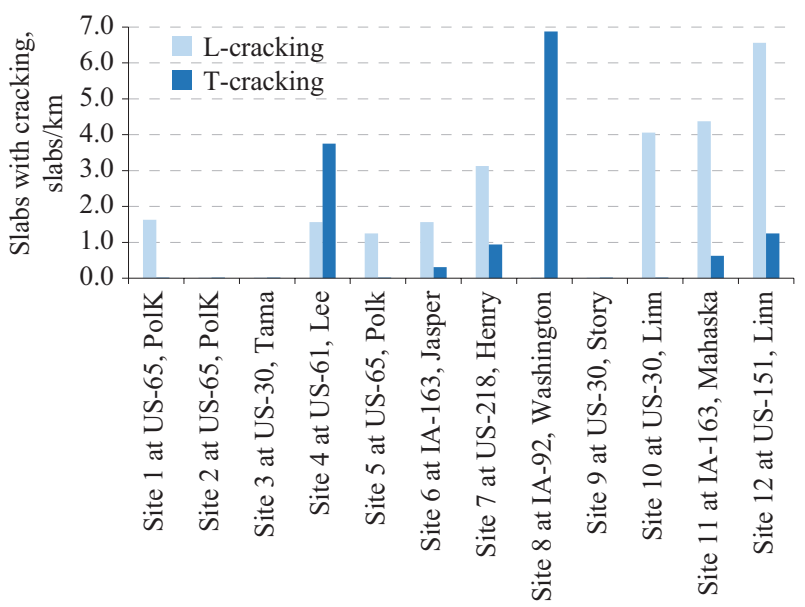

Figure 2. Number of slabs with longitudinal and transverse cracks 


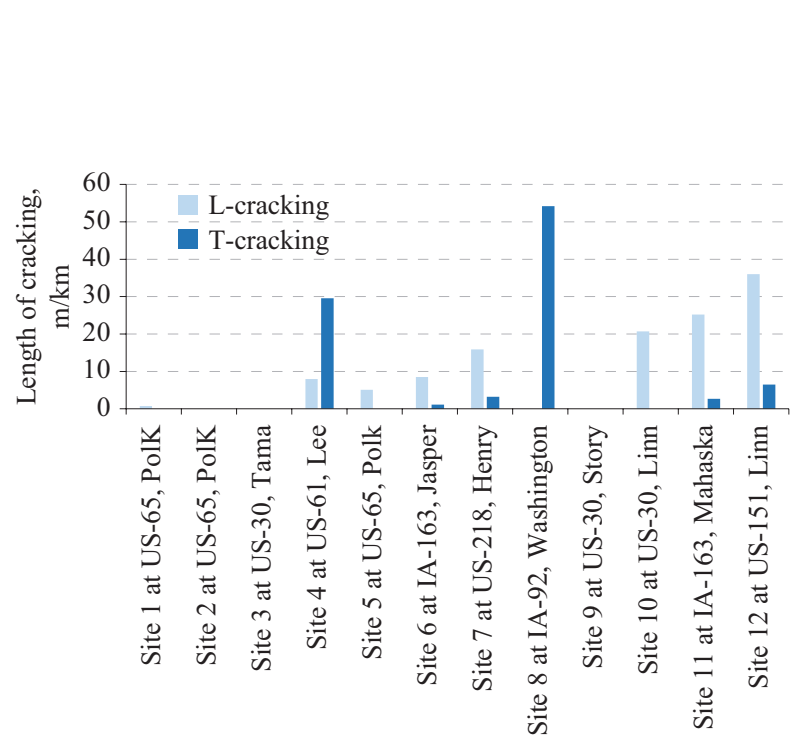

Figure 3. The total length of cracking at each site

transverse joints during a follow-up survey in early summer 2018. These cracks were short (around $0.10 \mathrm{~m}$ ) and located near right wheel paths. In addition, a few sites exhibited some mid-panel transverse cracks across both regular and widened adjacent slabs.

Figure 2 and Figure 3 describe the crack survey results in terms of the number of slabs cracked and total cracking length per kilometre, respectively. It indicates that longitudinal cracks are more dominant at most of the selected sites. Site 10, site 11, and site 12 exhibited a high level of longitudinal cracks (total length of cracking no less than $20 \mathrm{~m} / \mathrm{km}$ ), and site 4 through site 7 exhibited a moderate level of longitudinal cracks (total lengths of cracking more than $5 \mathrm{~m} / \mathrm{km}$ and below $20 \mathrm{~m} / \mathrm{km}$ ), and site 1 through site 3, site 8, and site 9 exhibited a low level of longitudinal cracks (total length of cracking below $5 \mathrm{~m} / \mathrm{km}$ ).

\subsection{Concrete coring}

To seek a better understanding of the development process of such longitudinal cracks, concrete cores were obtained by Iowa Dept of Transportation (Iowa DOT) crews from selected sites at crack locations and then examined. Figure 4 through Figure 6 show some representative cores taken from sites 6,10 , and 12 , respectively. The cores examined from these sites revealed that most cracks were top-down cracking, and some other cores exhibited full-depth cracking and split open upon being extracted. Although it was usually thought that bottom-up cracking resulting from edge loading was the principal failure mode for JPCPs, these studies indicated that top-down cracking could also be a dominant 
failure mode under some circumstances, depending on built-in curling and load configuration (Kim, 2010).

Additionally, the team of researchers did not observe visible aggregate segregation, vibrator trails, or excessive entrapped air voids by examining the concrete cores, which exhibited uniformly-distributed aggregates in their mixes, excluded vibration as a cause of the cracking problem. There were also no issues found that were associated with concrete early-age strength, because the cracks in the cores crossed the aggregate, in agreement with construction report results that all the concrete had satisfied strength-test requirements. Additionally, dowel bars were properly aligned at the middle depth of the PCC layer, perpendicular to the transverse joints.

\section{Discussion on cracking survey results}

\subsection{Effects of Jointed Plain Concrete Pavement construction practice on longitudinal cracking}

Even though the occurrence of longitudinal cracks is due to multiple relevant factors, it is customary to assume that longitudinal cracks are mainly associated with poor construction practices or foundation issues such as soil heaving and swelling, improper compaction of underlying layers, high coefficient of subbase friction, misaligned dowels, late saw cuts for joints, and improper vibration during paving (Ardani, Hussain, \& LaForce, 2003; Chen \& Won, 2007; Voigt, 2002). Although most induced longitudinal cracking that results from such poor construction practices appears during early stages of service life, in this study, these longitudinal cracks mostly appeared after 10-15 years of service on the widened slabs, inferring that these longitudinal cracks were more likely to result from a combination of pavement ageing and other causes.
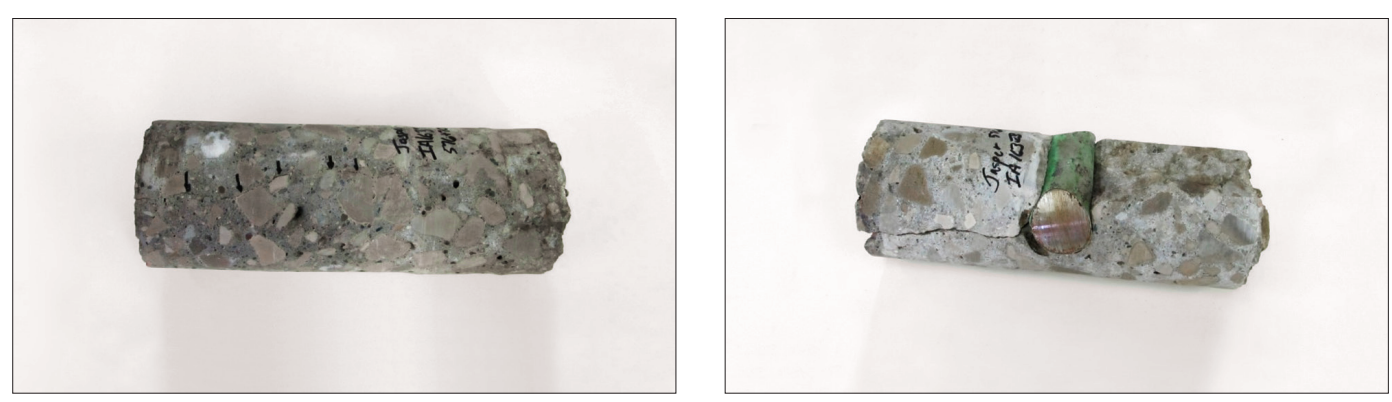

Figure 4. Concrete cores from site 6 at IA 163 

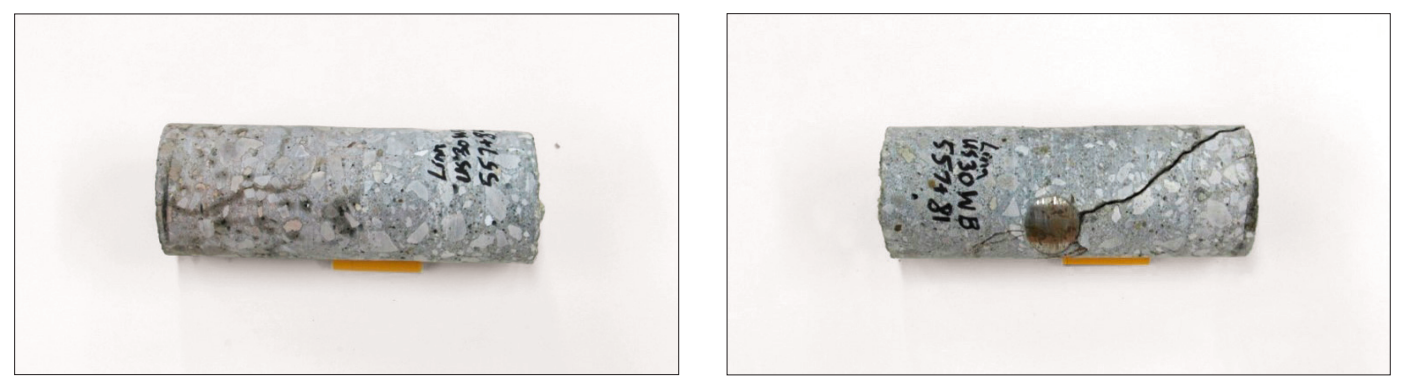

Figure 5. Concrete cores from site 10 at US 30

During the field investigation, no visible joint faulting was found, probably because these sites were all dowel-reinforced, and no pumping was observed at the sites too. No joint-related premature cracks were found at most investigated sites as well, indicating that the joints and dowels were performing properly at these sites. However, minor spalling was found at the groove edge of a transverse joint, extending into a longitudinal crack emanating along the wheel path at site 7 , and this kind of cracking pattern was probably due to a misaligned dowel bar since improper dowel-bar alignment has been found to result in pavement spalling and irregular cracks (Voigt, 2002).

Some arc-shapes longitudinal cracks were also found at site 4, site 7 , site 10 , and site 12 ; these were most likely caused by loss of support from underlying layers (Figure 1a). Since these sites also exhibited corner cracks, it seems reasonable to assume that they suffered from a combination of excessive traffic loads and loss of support from subgrade. In addition, since all the sites used granular subbase, friction was not the main cause of longitudinal cracking. Previous core examinations indicated the small likelihood of such cracks resulting from improper vibration and dowel bar misalignment.
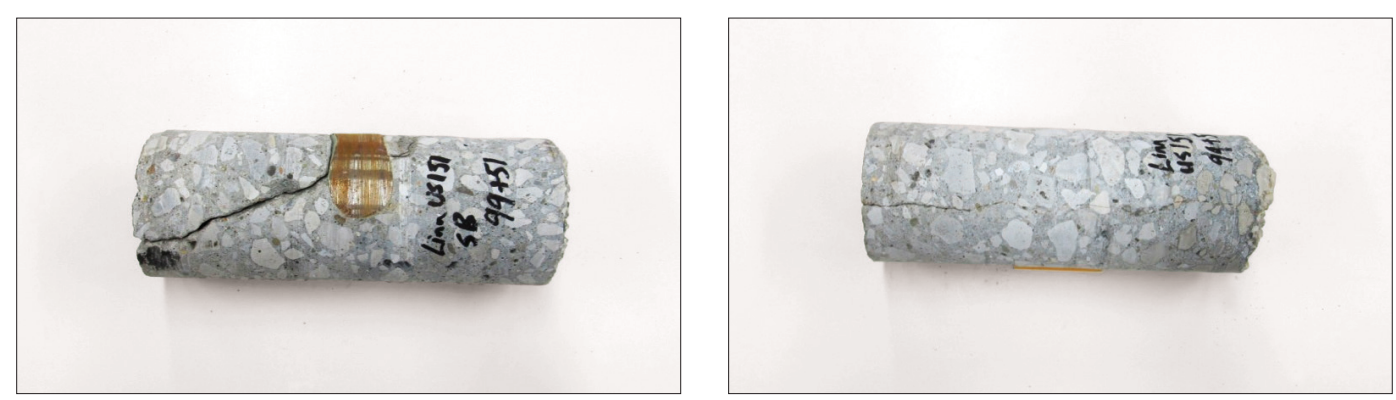

Figure 6. Concrete cores from site 12 at US 151 


\subsection{Effects of Jointed Plain Concrete Pavement design on longitudinal cracking}

Slab geometry has a significant impact on cracking propagation in JPCPs because it affects tensile stress distribution within panels. A previous study by Owusu-Ababio \& Schmitt (2013) indicated that $4.30 \mathrm{~m}$ (14 ft.) widened slabs exhibited fewer longitudinal cracks than $4.60 \mathrm{~m}$ (15 ft.) widened slabs in terms of percentage of cracked slabs. Another study by Xiao \& Wu (2018) showed an increase in slab cracking rate occurring when slab width increased from $3.70 \mathrm{~m}$ (12 ft.) to $4.60 \mathrm{~m}$ (15 ft.). It was noted that there were no $4.30 \mathrm{~m}$ (14 ft.) widened slabs investigated in this study because the Louisiana Dept of Transportation \& Development (Louisiana DOTD) did not adopt such slabs as their leading pavement design practice. However, both the Louisiana DOTD

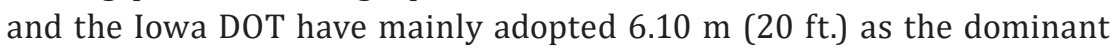
practice for joint spacing in JPCP construction, and this choice is more prone to longitudinal cracking compared to shorter joint spacing (Owusu-Ababio \& Schmitt, 2013). The high risk of longitudinal cracking of this practice is partially attributed to curling and warping issues since higher curling stresses will be induced as slab length and width increase.

It is also universally accepted that thicker slabs help mitigate cracks. Owusu-Ababio \& Schmitt (2013) suggested a ratio ranging from 1.20 (30.50 cm in thickness) to $1.50(24.10 \mathrm{~cm}$ in thickness) to minimise longitudinal cracking on $4.30 \mathrm{~m}$ (14 ft.) wide widened slabs. The ratios of the sites investigated in the study all were in this range, with a minimum thickness of $24.10 \mathrm{~cm}$ (Table 1). All the sites visited except for site 3 were also constructed using skewed joints, a prevalent design practice in the state of Iowa at the end of the 20th century. More detailed analysis of the impact from the skewed joint was performed using numerical modelling, as discussed in pertinent sections.

\subsection{Effects of shoulder type and traffic loads on longitudinal cracking}

Figure 7 shows the frequency and severity level of longitudinal cracks observed at the sites, based on total lengths of cracks and definitions following the LTPP distress manual (Miller \& Bellinger, 2014). The sites were ranked based on Average Annual Daily Truck Traffic volume $\left(\mathrm{AADT}_{\mathrm{T}}, \mathrm{vpd}\right)$ and categorised by shoulder type: tied PCC shoulder, HMA shoulder, and granular shoulder. It is generally concluded that higher truck traffic volume directly leads to a more significant number of more severe longitudinal cracks. Excessive traffic loads and passing activity will result in the rapid development of transverse 
tensile stresses and cause longitudinal cracks once the stresses exceed pavement strength. Moreover, Site 1 and site 2, with tied PCC shoulders, exhibited only a small number of low-severity longitudinal cracks, even though they had relatively higher truck traffic volume. Sites with HMA shoulders generally in terms of longitudinal cracks outperformed those with granular shoulders subjected to similar truck traffic volume. Sites 10 to 12 with granular shoulders presented the most significant number and most severe longitudinal cracks, and sites 8 and 9 with granular shoulders only slightly exhibited longitudinal cracks, possibly attributable to significantly lower truck traffic volume.

In general, tied PCC shoulders were used to provide transverse cracking control, and field observations in Louisiana have indicated that widened slabs with tied PCC shoulders are more susceptible to longitudinal cracks (Xiao \& Wu, 2018). However, general observations from this study indicate that widened slabs with tied PCC shoulders

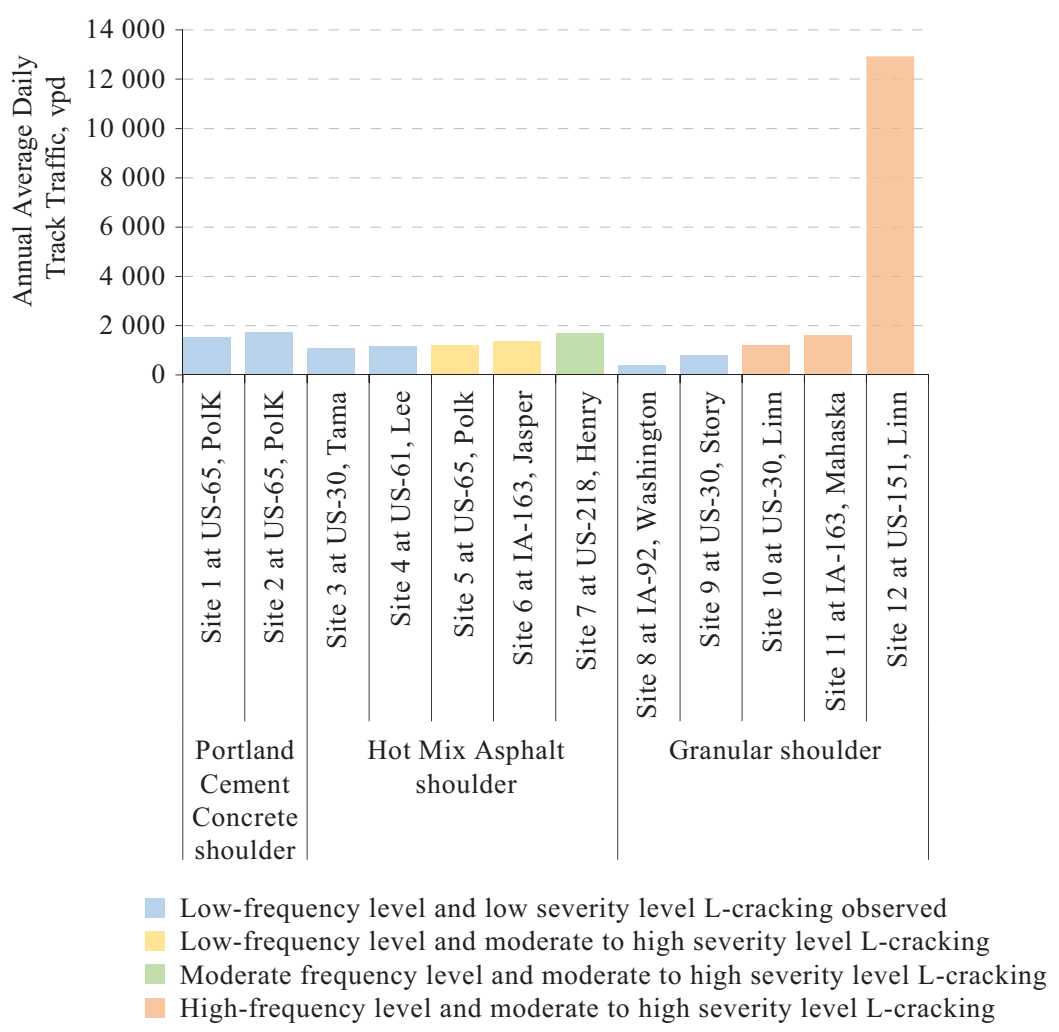

Figure 7. Frequency and severity level of widened slabs having longitudinal cracks 
have fewer longitudinal cracks than those with HMA shoulders or granular shoulders (Figure 7). This finding is attributed to several factors. First, in addition to a significant number of longitudinal cracks observed at Louisiana sites with tied PCC shoulders, there were also a significant number of corner breaks at those sites. The corner breaks imply that these sites probably suffered from the large load traffic accompanied by loss of support and poor joint load transfer capability, possibly associated with a great likelihood of longitudinal cracks (Xiao $\& \mathrm{Wu}, 2018$ ). Differing from the $4.30 \mathrm{~m}$ (14 ft.) widened slabs used for JPCPs in Iowa, Louisiana highways usually used $4.60 \mathrm{~m}$ (15 ft.) slab width with tied PCC shoulders, so a higher degree of curling and warping occurs due to greater slab width (Ceylan, Gopalakrishnan, Kim, Taylor, Alhasan, \& Yang, 2016; Rao \& Roesler, 2005). Yu, Smith, \& Darter (1995) also recommended $4.30 \mathrm{~m}$ (14 ft.) for slab width of widened pavements,

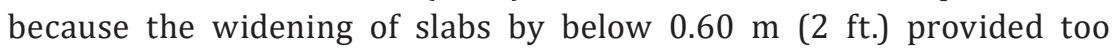
less stress reduction to improve pavement performance significantly. Widening of slabs by more than $0.60 \mathrm{~m}(2 \mathrm{ft}$.) lead to excessive curling stresses in the transverse direction that produces additional longitudinal cracks. This recommendation agrees with the findings of Owusu-Ababio \& Schmitt (2013) that $4.30 \mathrm{~m}$ (14 ft.) widened slabs experienced less longitudinal cracking than other widened slab sizes.

Additionally, unlike tied PCC shoulder, HMA shoulders and granular shoulders do not have the capability for load transfer between main lanes and shoulders. Although no edge or shoulder drop-off related issues were found at the sites with HMA shoulders, there were several transverse cracks observed on HMA shoulders near joint locations, possibly due to different rates of expansion and contraction between PCC and HMA materials (Owusu-Ababio \& Schmitt, 2004).

\subsection{Effects of curling and warping on longitudinal cracking}

Curling and warping are also the main contributors to longitudinal cracking. This unique deflection behaviour associated with temperature (curling) and moisture (warping) gradients will create weak points within slabs due to the induced slab curvature shape (Hiller \& Roesler, 2005; Stringer, Crawford, Fowler, Jirsa, Won, \& Whitney, 2008; Xiao \& Wu, 2018; Yu, Smith, \& Darter, 1995). It will exert tensile stresses at slab surface for upward curling or at slab bottom for downward curling due to surrounding restrains, thus resulting in top-down and bottom-up cracking, respectively. When combined with traffic loading, such stresses will be further magnified by several times, resulting in rapid cracking propagation (Ceylan, Gopalakrishnan, Kim, Taylor, Alhasan, \& Yang, 2016; Hiller \& Roesler, 2005). 
Curling and warping at the selected sites (sites 3, 9, 10, 12) were measured using a Terrestrial laser scanner during late fall 2015 (Figure 8). These sites were selected because sites 3 and 9 did not exhibit visible cracks, and site 10 and 12 exhibited a more significant number of longitudinal cracks. Terrestrial laser scanner provides slab profiling as accurate as a class 1 profiler (Chin \& Olsen, 2014; Yang, Alhasan, Ceylan, \& Kim, 2018) by producing three-dimensional (3D) point clouds that will be further modelled and visualized, enabling conduct of maximum deflection measurements along diagonal lines without necessity for traffic control in the field. In this study, morning and afternoon measurements were taken, and the degree of curling and warping were represented as curvature degree (Eq. (1)) to account for the rate of slope change along the slab length (Asbahan \& Vandenbossche, 2011; Byrum, 2005, 2009; Lederle, Lothschutz, \& Hiller, 2011; Vandenbossche \& Snyder, 2005; Yang, Ceylan, Alhasan, \& Kim, 2018). The detailed data collection process and calculation algorithm used have been explained in more details in previous studies (Yang, Alhasan, Ceylan, \& Kim, 2018, Yang, Ceylan, Alhasan, \& Kim, 2018; Yang, Ceylan, Gopalakrishnan, Kim, Taylor, \& Alhasan, 2018). Table 2 summarises the survey results for curling and warping measurements in terms of average curvature degree of scanned slabs along to different directions, where a positive value represents an upward slab curvature shape, and a negative value represents a downward slab curvature shape.

$$
k=\frac{\frac{\mathrm{d}^{2} z}{\mathrm{~d} x^{2}}}{\left[1+\left(\frac{\mathrm{d} z}{\mathrm{~d} x}\right)^{2}\right]^{\frac{3}{2}}}
$$

where $k$ - a degree of curvature, $1 / \mathrm{m} ; x$-distance, m; $z$ - elevation (m).

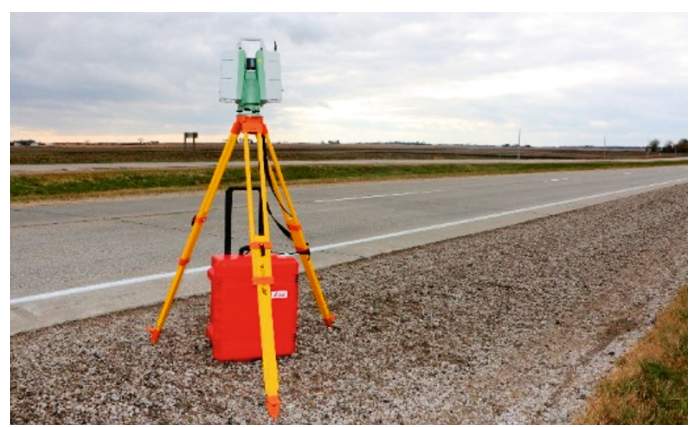

Figure 8. Terrestrial laser scanner used for curling and warping measurements at site 9 at US 30 
Table 2. Degree of curvature along with different directions

at the selected sites

\begin{tabular}{cccccccccc}
\hline & \multicolumn{8}{c}{ The average degree of curvature $\left(10^{-3} \mathbf{1} / \mathbf{m}\right)$} & \multicolumn{2}{c}{$\begin{array}{c}\text { Wheel } \\
\text { Location }\end{array}$} & \multicolumn{2}{c}{$\begin{array}{c}\text { Diagonal } \\
\text { directions }\end{array}$} & \multicolumn{2}{c}{$\begin{array}{c}\text { Longitudinal } \\
\text { edges }\end{array}$} & \multicolumn{2}{c}{$\begin{array}{c}\text { Transverse } \\
\text { edges }\end{array}$} & \multicolumn{2}{c}{\begin{tabular}{c} 
paths \\
\cline { 2 - 9 }
\end{tabular}} & AM & PM & AM & PM & AM & PM & AM & PM \\
\hline Site 3 at US 30 & -0.04 & N/A & -0.021 & N/A & -0.012 & N/A & -0.035 & N/A \\
Site 9 at US 30 & 0.03 & 0.018 & 0.022 & 0.020 & 0.040 & 0.032 & 0.032 & 0.028 \\
Site 10 at US 30 & 0.152 & 0.147 & 0.132 & 0.058 & 0.067 & 0.033 & 0.093 & 0.065 \\
Site 12 at US 151 & 0.324 & 0.314 & 0.140 & 0.125 & 0.102 & 0.010 & 0.156 & 0.146 \\
\hline
\end{tabular}

According to Table 2, maximum curvature usually is found along diagonal lines, and the sites exhibiting higher degrees of curling and warping (site 10 and 12) were associated with a more significant number of longitudinal cracks, as well as higher IRI and lower PCI (Table 1), compared to sites with lower degrees of curling and warping (site 3 and 9). The degree of curling and warping is influenced by many factors, such as temperature gradient, moisture gradient, shrinkage, built-in curling and warping, creep, slab geometry, concrete material properties and mix design, underlying layers, and on-site weather conditions (Ceylan, Gopalakrishnan, Kim, Taylor, Alhasan, \& Yang, 2016; Rao \& Roesler, 2005; Yu, Khazanovich, \& Darter, 2004). In this study, since limestone aggregates were used in concrete mixtures at all the sites, the coefficient of thermal expansion (CTE) is of concern in causing a high degree of curling and warping (Chen \& Won, 2007). Although all the scanned sites had the same slab dimensions, it has been reported that site 3 at US 30 exhibited a relatively lower level of built-in curling and warping (Kim, Gopalakrishnan, Ceylan, \& Wang, 2010). That site was constructed in the late afternoon, around 03:00 P.M., so its concrete hardened during the night with a measured low-temperature difference of below $2.8^{\circ} \mathrm{C}$ between slab surface and bottom. Such a low-temperature difference occurring during concrete setting will induce a low degree of built-in upward curling. Similarly, site 2 at US 65 was also constructed in the late afternoon at about 04:00 P.M, and these two sites (sites 2 and 3) built-in late afternoon outperformed other sites built in early morning, in terms of the number of cracks (Figure 7), probably because of the low degree of built-in curling and warping (Lederle, Lothschutz, \& Hiller, 2011; Rao \& Roesler, 2005). 


\section{Numerical modelling}

Use of skewed concrete joints to minimise vehicle-induced response and stresses on slabs (America Concrete Pavement Association, 2013) has become prevalent in several states in the US using JPCP construction since the end of the 20th century. Design of most highways in these states have applied a height to width ratio of $6: 1$ for skewed joints, often along with dowel bars to support alignment. However, previous studies have indicated that JPCPs with skewed joints will have a higher potential for slab cracking (Owusu-Ababio \& Schmitt, 2013; Rasmussen, Agosto, \& Cramer, 2007).

The longitudinal cracking potential between skewed and rectangular joints for JPCPs was assessed using 3D Finite Element Analyses (FEA). EverFE 2.25 software was chosen because it supports skewed joint modelling, aggregate interlock, joint shear transfer, and dowel joint

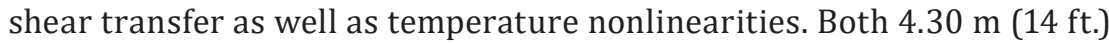
widened slabs with skewed and rectangular joints were modelled, and the joint spacing was set up as $6.10 \mathrm{~m}$ (20 ft.) for all cases. Threeaxle truckloads with both a single wheel (20 kips) and a tandem wheel (34 kips) were simulated. Axles were placed at different distances from slab edges and transverse joint to identify critical loading locations (see Figure 9). Temperature loads were applied by adjusting the temperature difference between the slab surface and bottom. The design parameters used for modelling are listed in Table 3.

Figure 10 shows the top tensile-stress distributions for skewed and rectangular-jointed widened JPCP cases. Three loading scenarios were compared: mechanical-load-only $\left(\Delta T=0{ }^{\circ} \mathrm{C}\right)$, mechanical load with temperature difference $\Delta T=-2.8^{\circ} \mathrm{C}\left(-5^{\circ} \mathrm{F}\right)$, and mechanical load with temperature difference $\Delta T=-5.6^{\circ} \mathrm{C}\left(-10^{\circ} \mathrm{F}\right)$. A red contour colour represents tensile stresses, and a blue contour colour represents compressive stresses. Numerical simulation results indicated that

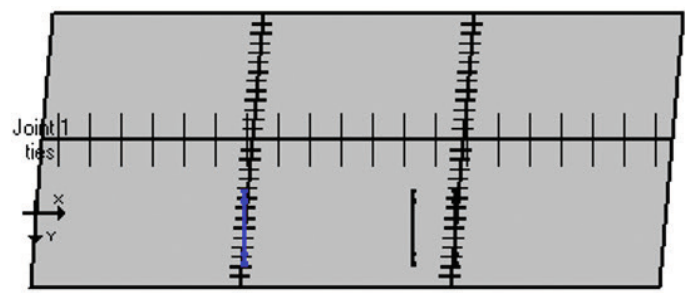

a) skewed joints

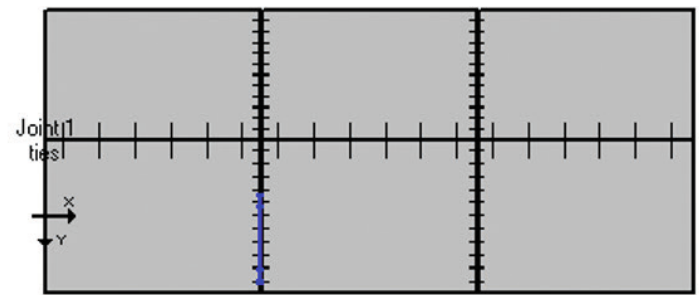

b) rectangular joints

Figure 9. Modelled Jointed Plain Concrete Pavements in EverFE 2.25 
critical stress positions were at transverse joints of the widened slabs at the lane edge. Maximum tensile stresses were induced at this critical position when half of the single and the back axles of the tandem axle were applied on the approaching slab and the other half on the leaving slabs. According to Figure 10, widened slabs with skewed joints generally exerted about $10 \%$ to $20 \%$ higher top tensile stresses compared to widened slab rectangular joints under the same loading scenarios. Tensile stresses also increased when the negative temperature gradient increased. The maximum tensile stresses were

Table 3. Input parameters for Finite Element Analyses

\begin{tabular}{|c|c|c|}
\hline & Layer Properties & Values \\
\hline Portland Cement & Joint spacing & $6.10 \mathrm{~m}$ \\
\hline \multirow[t]{9}{*}{ Concrete layer } & Widened slab width & $4.30 \mathrm{~m}$ \\
\hline & Slab thickness & $25.40 \mathrm{~cm}$ \\
\hline & Elastic modulus & $27580 \mathrm{MPa}$ \\
\hline & Poisson ratio & 0.2 \\
\hline & Coefficient of thermal expansion & $2.20 \cdot 10^{-5} \mathrm{~cm} /{ }^{\circ} \mathrm{C}$ \\
\hline & Unit weight & $2400 \mathrm{~kg} / \mathrm{m} 3$ \\
\hline & Skewed joint ratio & \\
\hline & Dowel bar properties & \\
\hline & Mesh size & $15.20 \mathrm{~cm}$ \\
\hline \multirow[t]{5}{*}{ Granular subbase } & Base thickness & $25.40 \mathrm{~cm}$ \\
\hline & Elastic modulus & $241 \mathrm{MPa}$ \\
\hline & Poisson ratio & 0.35 \\
\hline & Coefficient of thermal expansion & $2.30 \cdot 10^{-5} \mathrm{~cm} /{ }^{\circ} \mathrm{C}$ \\
\hline & Unit weight & $2038 \mathrm{~kg} / \mathrm{m} 3$ \\
\hline Subgrade & Modulus of subgrade reaction $(k)$ & $0.044 \mathrm{MPa} / \mathrm{mm}$ \\
\hline \multicolumn{2}{|c|}{ Mechanical and Temperature Loading Properties } & Values \\
\hline \multirow[t]{5}{*}{ Traffic load } & Single axle load & 9.10 ton \\
\hline & Tandem axle load & 15.40 ton \\
\hline & Load location - single axle & Every $0.60 \mathrm{~m}$ \\
\hline & Wander pattern - single axle & $\begin{array}{l}0 \mathrm{~m}, 0.30 \mathrm{~m} \text {, and } 0.60 \mathrm{~m} \text { away } \\
\text { from lane edge }\end{array}$ \\
\hline & $\begin{array}{l}\text { Long term load transfer efficiency } \\
\text { (LTE) }\end{array}$ & $70 \%$ \\
\hline \multirow[t]{2}{*}{ Temperature load } & Temperature difference & from $\mathrm{O}^{\circ} \mathrm{C}$ to $-5.6^{\circ} \mathrm{C}\left(-10^{\circ} \mathrm{F}\right)$ \\
\hline & & with an increment of $1.1^{\circ} \mathrm{C}\left(-2^{\circ} \mathrm{F}\right)$ \\
\hline
\end{tabular}



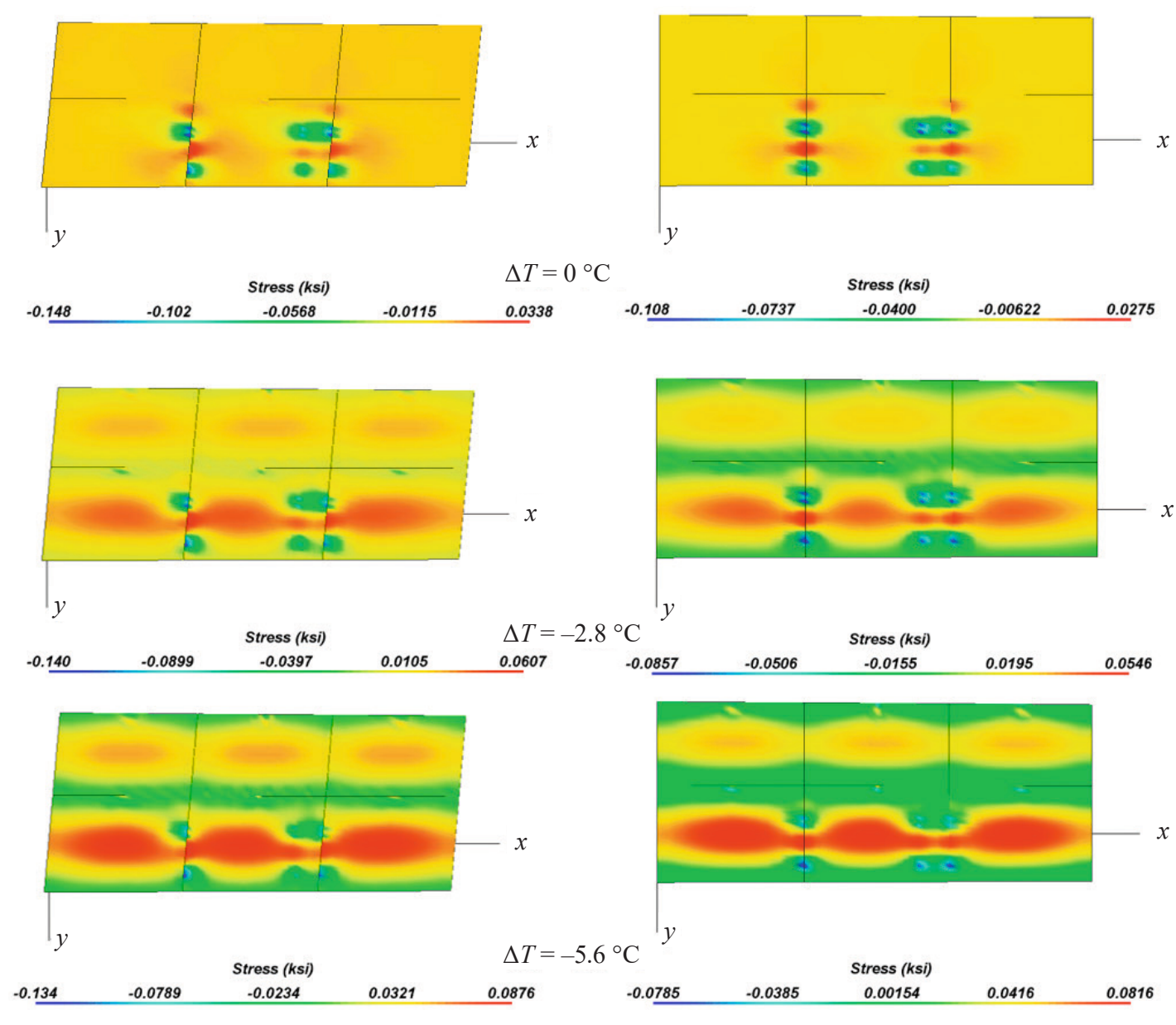

Skewed joint

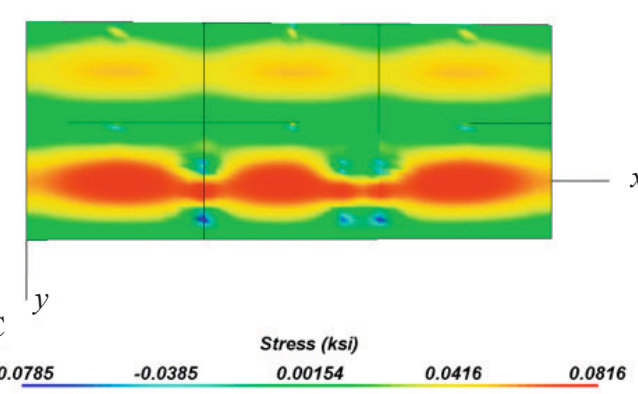

Rectangular joint

Figure 10. Comparison of stresses distributions between skewed

and rectangular jointed slabs

approximately increased by 2.6 times and 3 times when the temperature difference changed from $0{ }^{\circ} \mathrm{C}$ to $-5.6{ }^{\circ} \mathrm{C}$ for skewed joint and rectangular joint scenarios, respectively. This FEA results substantiated the fact that JPCPs with skewed joints have higher potential for longitudinal cracking. The load cantilever generated from skewed joints contributes to this finding because it corresponds to imparting excessive tensile strain within the slab. Consequently, in combination with widened slabs and excessive truck traffic, JPCPs with skewed joints increase cracking potential. 


\section{Conclusions}

This study was carried out to identify possible causes of longitudinal cracking in Jointed Plain Concrete Pavements with widened slabs. Based field crack survey, curling and warping measurements, concrete coring as well as finite-element analysis, the key findings from this study are summarised as follows:

1. top-down longitudinal cracks were observed in widened Jointed Plain Concrete Pavements and were mainly located within traffic lanes about from $0.60 \mathrm{~m}$ to $1.20 \mathrm{~m}$ (from $2 \mathrm{ft}$. to $4 \mathrm{ft}$.) from slab edges and parallel to the traffic direction;

2. poor construction practices such as inadequate support from underlying layers caused longitudinal cracking;

3. sites subjected to higher truck traffic volume exhibited a more significant number of longitudinal cracks;

4. sites producing higher degrees of curling and warping measurements exhibited significantly more longitudinal cracks than sites with lower degrees of curling and warping;

5. sites with tied Portland Cement Concrete shoulders generally outperformed those with Hot Mix Asphalt and granular shoulders, even though the sites with tied Portland Cement Concrete shoulders experienced relatively higher traffic volume;

6. the site constructed in the late afternoon, where concrete set during night-time and led to less built-in curling, only slightly exhibited longitudinal cracks;

7. the results of the Finite Element Analysis indicate that, under all loading scenarios, pavements constructed with skewed joints are prone to longitudinal cracks compared to those with rectangular joints.

Although widened slabs have been widely accepted as providing an effective means for controlling transverse cracks, highway agencies have not well studied longitudinal cracks on widened slabs yet. Causes of longitudinal cracks include a combination of excessive loads, high degrees of curling and warping, inadequate subgrade support, pavement

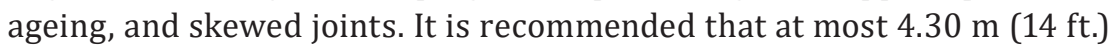
for the width of widened slabs to minimise curling and warping stresses, and late-afternoon paving to avoid excessive upward built-in curling is also recommended. Skewed joints and granular shoulders should be avoided for widened Jointed Plain Concrete Pavements, especially when a high volume of truck traffic is anticipated. 


\section{Acknowledgements}

The authors would like to thank the Iowa Dept of Transportation (Iowa DOT) for sponsoring this research (TR-700). The Technical Advisory Committee (TAC) members of this project, Ben Behnami, Chris Brakke, Vanessa Goetz, Todd Hanson, Kevin Merryman and Jason Omundson of Iowa DOT; Jacob Thorius of Washington County, Iowa; Greg Mulder of Iowa Concrete Paving Association (ICPA); Gordon Smith of ISU CP Tech Center and John Cunningham of Snyder \& Associates, Inc. are gratefully acknowledged for their guidance. The contents of this paper reflect the views of the authors who are responsible for the facts and accuracy of the data presented within. The contents do not necessarily reflect the official views and policies of the Iowa DOT. This paper does not constitute a standard, specification, or regulation.

\section{REFERENCES}

America Concrete Pavement Association (ACPA) (2013). 50th Anniversary.

Applied Research Associates Inc. (ARA) \& ERES Consultants Division (2004). Guide for Mechanistic-Empirical Design of New and Rehabilitated Pavement Structures. Final Rep., NCHRP Project 1-37A.0

Ardani, A., Hussain, S., \& LaForce, R. (2003, August). Evaluation of premature PCC pavement longitudinal cracking in Colorado. In Proceedings of the 2003 Mid-Continent Transportation Research Symposium (pp. 1-9).

Asbahan, R. E., \& Vandenbossche, J. M. (2011). Effects of temperature and moisture gradients on slab deformation for jointed plain concrete pavements. Journal of Transportation Engineering, 137(8), 563-570. https://doi.org/10.1061/(ASCE)TE.1943-5436.0000237

Byrum, C. R. (2005). The effect of slab curvature on IRI values for jointed concrete pavements. International Journal of Pavement Engineering, 1(1), 23-32.

Byrum, C. R. (2009). Measuring Curvature in Concrete Slabs and Connecting the Data to Slab Modeling Theory. Transportation Research Record, 2094(1), 79-88. https://doi.org/10.3141/2094-09

Ceylan, H., Gopalakrishnan, K., Kim, S., Taylor, P., Alhasan, A. A., \& Yang, S. (2016). Impact of Curling and Warping on Concrete Pavement. Report No. IHRB Project TR-668, Iowa Dept of Transportation, Ames, Iowa.

Ceylan, H., Kim, S., Yang, S., Kaya, O., Gopalakrishnan, K., Taylor, P., \& Yang, Z. (2018). Prevention of Longitudinal Cracking in Iowa Widened Concrete Pavement (No. IHRB Project TR-700). Iowa State University. Institute for Transportation.

Chen, D. H., \& Won, M. (2007). Field investigations of cracking on concrete pavements. Journal of Performance of Constructed Facilities, 21(6), 450-458. https://doi.org/10.1061/(ASCE)0887-3828(2007)21:6(450) 
Chin, A. \& Olsen, M. J. (2014). Evaluation of technologies for road profile capture, analysis, and evaluation. Journal of Surveying Engineering, 141(1), 1-13. https://doi.org/10.1061/(ASCE)SU.1943-5428.0000134.

Hiller, J. E., \& Roesler, J. R. (2005). Determination of critical concrete pavement fatigue damage locations using influence lines. Journal of Transportation Engineering, 131(8): 599-607. https://doi.org/10.1061/(ASCE)0733-947X(2005)131:8(599)

Iowa Dept of Transportation (2015). Pavement Management Information Systems (PMIS). Iowa Department of Transportation, Ames, IA.

Kim, H. B. (2010). Top-Down Cracking of Jointed Plain Concrete Pavements. Journal of the Eastern Asia Society for Transportation Studies, 8, 1529-1541. https://doi.org/10.11175/easts.8.1529

Kim, S., Gopalakrishnan, K., Ceylan, H., \& Wang, K. (2010). Early-age response of concrete pavements to temperature and moisture variations. The Baltic Journal of Road and Bridge Engineering, 5(3), 132-138. https://doi.org/10.3846/bjrbe.2010.19

Lederle, R. E. (2014). Development of a Longitudinal Cracking Fatigue Damage Model for Jointed Plain Concrete Pavements Using the Principles of Similarity. Doctoral Dissertation, University of Minnesota.

Lederle, R. E., Lothschutz, R. W., \& Hiller, J. E. (2011). Field evaluation of built-in curling levels in rigid pavements (No. MN/RC 2011-16). Minnesota Dept of Transportation, Saint Paul, Minnesota.

Miller, J. S., \& Bellinger, W. Y. (2014). Distress identification manual for the long-term pavement performance program (No. FHWA-HRT-13-092). United States. Federal Highway Administration. Office of Infrastructure Research and Development.

Owusu-Ababio, S., \& Schmitt, R. (2004). Transverse cracking progression in asphalt shoulders adjacent to concrete pavements. In Proceedings of the PRO 37: 5th International RILEM Conference on Cracking in Pavements Mitigation, Risk Assessment and Prevention, Limoges, France (pp. 467).

Owusu-Ababio, S., \& Schmitt, R. (2013). Longitudinal Cracking in Widened Portland Cement Concrete Pavements. Report No. 0092-12-05, Wisconsin Dept of Transportation, Madison, Wisconsin.

Raghavendra, A., Collier, Z., \& Rupnow, T. (2017). Evaluation of cores from I-49 near LA 1 in Shreveport. Report No. FHWA/LA.17/17-01TA-C. Louisiana Dept of Transportation and Development, Baton Rouge, Louisiana.

Rao, S., \& Roesler, J. R. (2005). Characterization of Effective Built-In Curling and Concrete Pavement Cracking on the Palmdale Test Sections. University of Illinois at Urbana-Champaign, Urbana, Illinois.

Rasmussen, R. O., Agosto, A. P., \& Cramer, S. M. (2007). Analysis of concrete pavement joints to predict the onset of distress. Wisconsin Highway Research Program, University of Wisconsin--Madison.

Sawan, J. S., Darter, M. I., \& Dempsey, B. J. (1982). Structural Analysis and Design of PCC Shoulders (No. FHWA/RD-81/122). United States. Federal Highway Administration. 
Stringer, M., Crawford, T., Fowler, D. W., Jirsa, J. O., Won, M. C., \& Whitney, D. P. (2008). Assessment and rehabilitation methods for longitudinal cracks and joint separations in concrete pavement (No. FHWA/TX-09/0-5444-2).

Vandenbossche, J. M., \& Snyder, M. B. (2005). Comparison between measured slab profiles of curled pavements and profiles generated using the finite element method. In Eighth International Conference on Concrete Pavements American Association of State Highway and Transportation Officials (AASHTO), American Concrete Pavement Association, Cement Association of Canada Colorado, Dept of Transportation, Concrete Reinforcing Steel Institute, Federal Highway Administration, Portland Cement Association, Purdue University, Transportation Research Board.

Voigt, G. F. (2002). Early cracking of concrete pavement-causes and repairs. In 2002 Federal Aviation Administration (FAA) Airport Technology Transfer Conference.

Westergaard, H. M. (1926). Stresses in concrete pavements computed by theoretical analysis. Public Roads, 7(2), 25-35.

Xiao, D. X., \& Wu, Z. (2018). Longitudinal cracking of jointed plain concrete pavements in Louisiana: Field investigation and numerical simulation. International Journal of Pavement Research and Technology, 11(5), 417-426. https://doi.org/10.1016/j.ijprt.2018.07.004

Xu, C., \& Cebon, D. (2017). Analysis of Cracking in Jointed Plain Concrete Pavements: [summary report] (No. FHWA-HRT-16-073). United States. Federal Highway Administration. Office of Research, Development, and Technology.

Yang, S., Alhasan, A., Ceylan, H., \& Kim, S. (2018). Accuracy assessment of light detection and ranging system measurements for jointed concrete pavement surface geometry. In TRB 97th Annual Meeting of Compendium of Papers, Washington, DC, 7-11 January 2018.

Yang, S., Ceylan, H., Alhasan, A., \& Kim, S. (2018). Three-dimensional geometric modelling for curvature-based concrete slab shape analysis using point cloud data. The 9th International DUT-Workshop on Research and Innovations for Design of Sustainable and Durable Concrete Pavements, Potsdam, Germany, 17-18 June 2018.

Yang, S., Ceylan, H., Gopalakrishnan, K., Kim, S., Taylor, P. C., \& Alhasan, A. (2018). Characterization of environmental loads related concrete pavement deflection behavior using Light Detection and Ranging technology. International Journal of Pavement Research and Technology, 11(5), 470-480. https://doi.org/10.1016/j.ijprt.2017.12.003

Yu, H. T. Khazanovich, L., \& Darter, M. I. (2004). Consideration of JPCP curling and warping in the 2002 design guide. In TRB 83rd Annual Meeting of Compendium of Papers, Washington, DC, 11-15 January 2004.

Yu, H. T., Smith, K. D., \& Darter, M. I. (1995). Effects of Tied PCC Shoulder and Widened Slabs on Performance of JPCP. Report No. CDOT-DTD-R-95-18. Colorado Dept of Transportation, Denver, Colorado. 